Wright State University

CORE Scholar

Physics Faculty Publications

Physics

$5-2-2009$

\title{
Polarity-Related Asymetry At ZnO Surfaces and Metal interfaces
}

\author{
Y. F. Dong \\ Z-Q. Fang \\ David C. Look \\ Wright State University - Main Campus, david.look@wright.edu \\ Daniel R. Doutt \\ M. J. Hetzer
}

See next page for additional authors

Follow this and additional works at: https://corescholar.libraries.wright.edu/physics

Part of the Physics Commons

\section{Repository Citation}

Dong, Y. F., Fang, Z., Look, D. C., Doutt, D. R., Hetzer, M. J., \& Brillson, L. J. (2009). Polarity-Related

Asymetry At ZnO Surfaces and Metal interfaces. Journal of Vacuum Science \& Technology B, 27 (3), 1710-1716.

https://corescholar.libraries.wright.edu/physics/5

This Article is brought to you for free and open access by the Physics at CORE Scholar. It has been accepted for inclusion in Physics Faculty Publications by an authorized administrator of CORE Scholar. For more information, please contact library-corescholar@wright.edu. 
Authors

Y. F. Dong, Z-Q. Fang, David C. Look, Daniel R. Doutt, M. J. Hetzer, and L. J. Brillson

This article is available at CORE Scholar: https://corescholar.libraries.wright.edu/physics/5 


\section{Polarity-related asymetry at $\mathrm{ZnO}$ surfaces and metal interfaces}

Yufeng Donga)

Department of Electrical and Computer Engineering, The Ohio State University, Columbus, Ohio 43210

Z.-Q. Fang and D. C. Look

Semiconductor Research Center, Wright State University, Dayton, Ohio 45435

D. R. Doutt and M. J. Hetzer

Department of Physics, The Ohio State University, Columbus, Ohio 43210

L. J. Brillson

Department of Electrical and Computer Engineering, The Ohio State University, Columbus, Ohio 43210;

Department of Physics, The Ohio State University, Columbus, Ohio 43210; and Center for Materials

Research, The Ohio State University, Columbus, Ohio 43210

(Received 8 December 2008; accepted 23 March 2009; published 29 May 2009)

Clean $\mathrm{ZnO}(0001) \mathrm{Zn}$ - and (000 $\overline{1})$ O-polar surfaces and metal interfaces have been systematically studied by depth-resolved cathodoluminescence spectroscopy, photoluminescence, current-voltage and capacitance-voltage measurements, and deep level transient spectroscopy. Zn-face shows higher near band edge emission and lower near surface defect emission. Even with remote plasma decreases of the $2.5 \mathrm{eV}$ near surface defect emission, (0001)-Zn face emission quality still exceeds that of $(000 \overline{1})$-O face. The two polar surfaces and corresponding metal interfaces also present very different luminescence evolution under low-energy electron beam irradiation. Ultrahigh vacuum-deposited $\mathrm{Au}$ and $\mathrm{Pd}$ diodes on as-received and $\mathrm{O}_{2} / \mathrm{He}$ plasma-cleaned surfaces display not only a significant metal sensitivity but also a strong polarity dependence that correlates with defect emissions, traps, and interface chemistry. Pd diode is always more leaky than Au diode due to the diffusion of $\mathrm{H}$, while $\mathrm{Zn}$-face is better to form Schottky barrier for Au compared with O-face. A comprehensive model accounts for the metal-and polarity-dependent transport properties. (C) 2009 American Vacuum Society. [DOI: 10.1116/1.3119681]

\section{INTRODUCTION}

As one of the most important candidates for next generation semiconductor devices, $\mathrm{ZnO}$ has been studied extensively in recent years. ${ }^{1}$ Although metal/ZnO interfaces are essential to all $\mathrm{ZnO}$ electronic device applications, it still remains a challenge to fabricate high quality and thermally stable $\mathrm{ZnO}$ contacts. Their electronic properties have only recently been explored in detail. ${ }^{2-7}$ The famous SchottkyMott theory is seldom obeyed by metals on $\mathrm{ZnO}$, i.e., their Schottky barrier heights are not proportional to their work functions. ${ }^{8}$ Our previous studies revealed the importance of surface and near surface effects, including surface adsorbates, near-interface native defects, interface chemical bonding, and thermally induced interface chemical interactions at metal/ZnO contacts. ${ }^{3,9-12}$ Now, we are correlating polarityrelated surface and near surface defects and chemical reactions with electronic properties. ${ }^{13}$ Surface polarity plays important role in wurtzite semiconductor devices. Significant polarity-related effects have been found in GaN-based devices. ${ }^{14}$ Likewise, homoepitaxial $\mathrm{ZnO}$ layers grown on polar surfaces have very different optical properties and impurity levels. ${ }^{15}$ The stabilization mechanisms of $\mathrm{Zn}(0001)$ - or $\mathrm{O}(000 \overline{1})$-terminated faces have been a source of controversy for quite some time. ${ }^{16}$ Differences between hydrothermal

\footnotetext{
a) Author to whom correspondence should be addressed; electronic mail: dong.70@osu.edu
}

$\mathrm{ZnO}$ polar surfaces were ascribed to surface band bending induced by spontaneous polarization, ${ }^{17}$ while melt-grown $\mathrm{ZnO}$ exhibits only a small difference in band bending. ${ }^{18}$ However, it is still not clear which polar face should give better Schottky contacts because few comparisons between two polarities exist regarding their surface optical properties, defect concentrations, metal reactivities with various metal contacts, and Schottky barrier heights.

In this study, we probed the polarity- and metal-dependent properties of (0001) Zn- and (000 $\overline{1})$ O-polar surfaces of single crystalline $\mathrm{ZnO}$ with very low bulk defect grown by vapor phase process and their metal contacts by using nanoscale depth-resolved cathodoluminescence spectroscopy (DRCLS) coupled with surface science and electronic transport techniques.

\section{EXPERIMENT}

Vapor-phase grown single crystal $\mathrm{ZnO}$ samples from $\mathrm{ZN}$ Technology Inc. and polished chemomechanically on both the $(0001)$ and $(000 \overline{1})$ faces had mid- $10^{16} \mathrm{~cm}^{-3}$ carrier concentration and $220 \mathrm{~cm}^{2} / \mathrm{V} \mathrm{s}$ Hall mobility at $300 \mathrm{~K}^{19}$ All samples were ultrasonically cleaned in acetone, dimethysulfuoxide, methanol, isopropyl alcohol, and de-ionized water for $5 \mathrm{~min}$, respectively, then nitrogen blow dried. These samples are referred as "as-received." We used remote oxygen plasma (ROP) treatment to remove surface adsorbates and subsurface impurities and defects such as oxygen 
vacancies. ${ }^{2,3}$ For the plasma-cleaned samples, both $\mathrm{Zn}$ - and $\mathrm{O}$-faces from separate halves of the same as-received $\mathrm{ZnO}$ crystal were ROP processed for 1-2 h. Subsequent atomic force microscopy measurements show only negligible increase in surface roughness. In general, the $\mathrm{Zn}$-face is smoother than O-face $(\mathrm{rms} 0.2 \mathrm{~nm}$ versus $0.4 \mathrm{~nm}$ ) although both surfaces have very smooth surfaces. Both surfaces show no atomic step edges, grain boundaries, or polishing scratches, no matter ROP cleaned or not. Arrays of metal diodes ( $\mathrm{Au}, \mathrm{Pd}$, and $\mathrm{Ta}, 0.4 \mathrm{~mm}$ diameter, $30 \mathrm{~nm}$ thick) were e-beam deposited in situ on two ROP-cleaned and asreceived polar surfaces at mid- $10^{-9}$ Torr pressures. We note the importance of in situ metal deposition on clean surfaces within the same plasma chamber. It has been recognized that $\mathrm{ZnO}$ surfaces are very reactive even under atmosphere. The surface adsorbates (primarily $\mathrm{OH}^{-}$) will form a surface conductive layer, degrade metal contacts, and introduce Schottky barrier diode (SBD) leakage. The UHV e-beam deposition was kept at a slow rate $(\sim 1 \mathrm{~nm} / \mathrm{min})$ to avoid possible metal-deposition-induced surface damage. Subsequently, we prepared Ohmic contacts on the entire back side of each $\mathrm{ZnO}$ piece using e-beam deposited $(40 / 60 / 30 \mathrm{~nm}) \mathrm{Ti} / \mathrm{Ni} / \mathrm{Au}$ film. DRCLS, remote $\mathrm{O}_{2} / \mathrm{He}$ plasma (ROP) processing, and deep level transient spectroscopy (DLTS) are described elsewhere. ${ }^{3,20}$

\section{RESULTS AND DISCUSSION}

Figures 1(a) and 1(b) show DRCL spectra for as-received and $2 \mathrm{~h}$ ROP-treated $\mathrm{Zn}$ - and O-faces, respectively. Electron beam energies $E_{B}$ varied from 1 to $5 \mathrm{keV}$, corresponding to depths $U_{0}$ of peak electron-hole pair creation rates increasing from 10 to $100 \mathrm{~nm}$, respectively. Although spectral features appear similar, the $\mathrm{Zn}$ face displays four times higher band edge (NBE, at $3.45 \mathrm{eV}$ ) emission throughout the near surface region. ROP does not change the spectral features. Defect emission is always dominated by the $2.5 \mathrm{eV}$ "green" emissions and no apparent new defect emission appears after $2 \mathrm{~h}$ ROP. Figure 2 shows relative defect intensity changes versus depth. The CL intensities $\left(I_{D}\right.$ or $\left.I_{\mathrm{NBE}}\right)$ were read from their maximum peak values. Defect intensities are normalized relative to NBE intensities. The general trend of $I_{D} / I_{\mathrm{NBE}}$ decrease from surface indicates more oxygen vacancy defects in the surface region. The $2.5 \mathrm{eV}$ green defect $\left(I_{D}\right)$ and $3.45 \mathrm{eV}$ near band edge $\left(I_{\mathrm{NBE}}\right)$ emission intensity exhibit significant polarity-related differences. The $\mathrm{O}$ face has two times higher defect intensity than the $\mathrm{Zn}$ face even after ROP cleaning. As-received surfaces show similar polarity effects. Figure 2 also shows that ROP cleaning effectively decreases the O-face $I_{D} / I_{\mathrm{NBE}}$ ratio, while changing the $\mathrm{Zn}$-face ratio only slightly. We previously assigned the $2.5 \mathrm{eV}$ peak to defects related to oxygen vacancies. ${ }^{9}$ The results indicate that the $\mathrm{O}$-face has more oxygen vacancies than the $\mathrm{Zn}$-face.

In cathodoluminescence measurements, we found a complex polarity- and metal-dependent luminescence evolutions under low electron beam irradiation of our scanning electron microscope. Electron beams with 2 and $5 \mathrm{kV}$ energy were applied to bare surfaces and metal diodes, respectively,

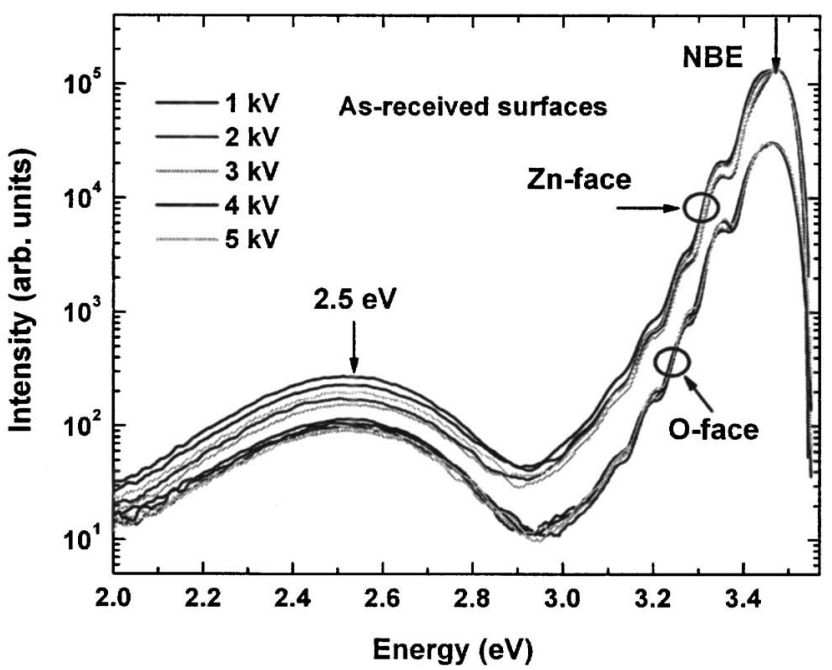

(a)

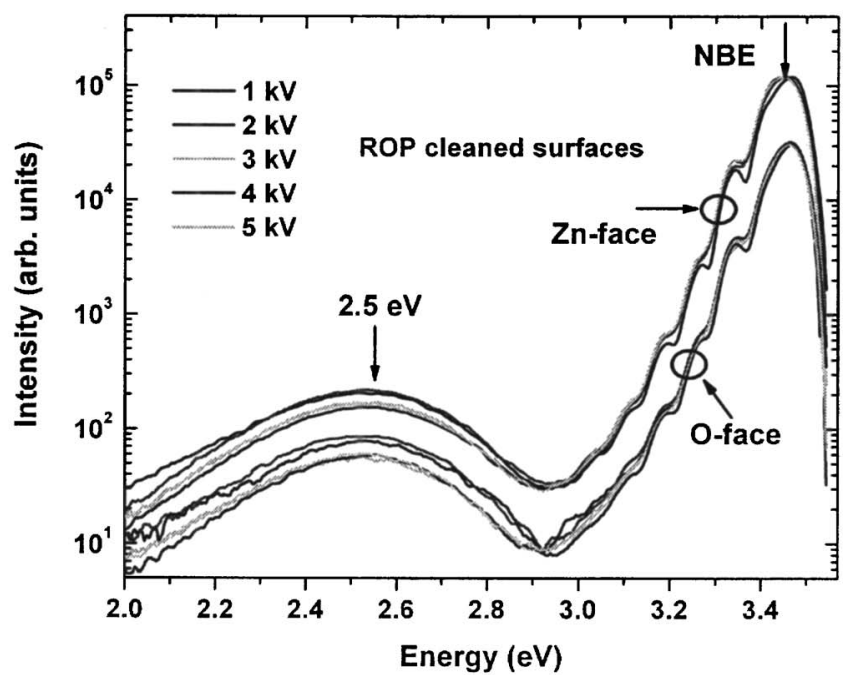

(b)

FIG. 1. DRCL spectra for (a) as-received Zn- and O-face (b) ROP cleaned $\mathrm{Zn}$ - and O-faces.

which give the same probing depth in $\mathrm{ZnO}(\sim 24 \mathrm{~nm})$. Figure 3 shows the time dependence of NBE emission for bare $\mathrm{Zn}$ - and O-face and their diodes. For Zn-face, the NBE intensity first increases slightly and then changes little after $50 \mathrm{~s}$ exposure. However, the O-face behaves very different, decreasing sharply by a factor of 6 at the first $100 \mathrm{~s}$ exposure. Similar polarity effects were found for hydrothermally grown $\mathrm{ZnO}$ single crystal samples, where the decrease in NBE intensity was attributed to metastable bulk defect reactions. ${ }^{21}$ It is reasonable that $\mathrm{O}$-face, with much more defects, shows the sharp decrease in NBE intensity. The time dependence of NBE intensity for metal diodes on two polar surfaces is more complicated. There are two important features: (i) For Au diode, the NBE intensity is stable on the $\mathrm{Zn}$-face while on the O-face, it is stable only for $\sim 60 \mathrm{~s}$, decreasing exponentially thereafter; and (ii) for Pd diodes, the intensity increases on the $\mathrm{Zn}$-face while it increases slightly and then exponentially decreases on the O-face. The 


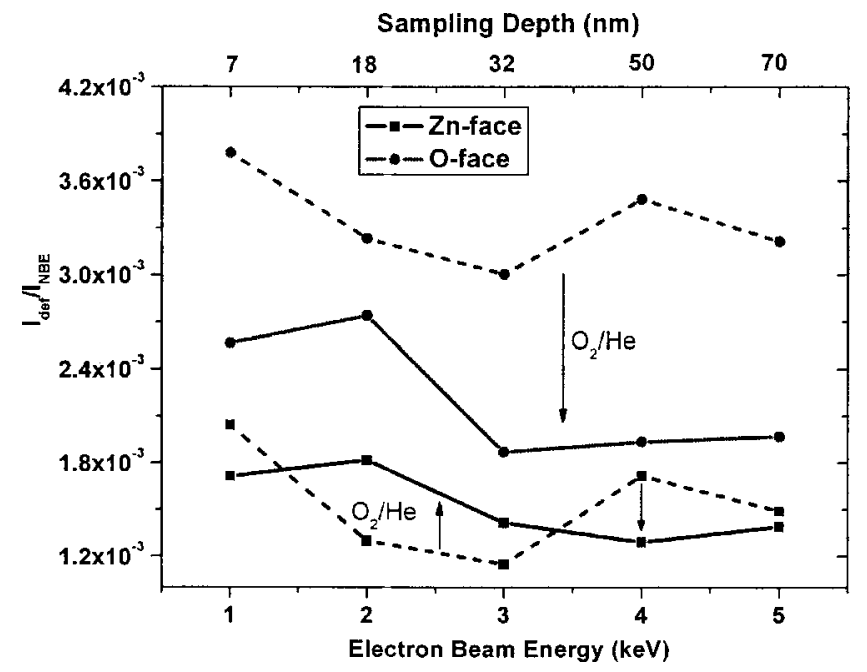

FIG. 2. Relative defect intensity changes vs depth for (0001) Zn and (0001) $\mathrm{O}$ faces.

mechanisms for the complicated electron-beam-irradiationinduced processes are related not only to the metastable near surface defects induced by e-beam but also to the metal/ZnO interface chemistry, which are still under investigation. Nevertheless, the different behavior of $\mathrm{Zn}$ - and O-face shows the polarity effects and serves as a signature for two polar surfaces. We note that the DRCL spectra in Figs. 1 and 2 were recorded by a charge coupled device detector with $0.2 \mathrm{~s}$ e-beam exposure, where the mentioned time dependence is negligible.

The higher $I_{D}$ of $2.5 \mathrm{eV}$ defects in cathodoluminescence spectroscopy, previously associated with $\mathrm{O}$ vacancies, ${ }^{9,10}$ induces different transport behavior on the O- versus $\mathrm{Zn}$-facemetal diodes. All the metal diodes ( $\mathrm{Au}, \mathrm{Pd}$, and $\mathrm{Ta}$ ) deposited on as received surfaces are Ohmic and there is an Ohmic to rectifying transition for $\mathrm{Au}$ and Pd diodes on ROP surfaces. However, electrical properties show both metal and polarity dependence. First, resistivity of two Au Ohmic contacts on the $\mathrm{Zn}$-face increases monotonically while that on O-face decreases slightly as temperature decreases from 300 to $100 \mathrm{~K}$, as shown in Fig. 4. This indicates more near surface defects at the $\mathrm{O}$ face than at the $\mathrm{Zn}$ face, consistent with the DRCLS results. Since gold contacts on as-received $\mathrm{O}$-faces are Ohmic, the decrease in resistance with decreasing temperature is due to a mobility increase in bulk $\mathrm{ZnO}$, assuming constant carrier concentration. The effects of vacuum activated layers, observed on highly resistive, compensated $\mathrm{ZnO}$ crystals, ${ }^{22,23}$ may not play the dominant role here. However, gold contacts on the $\mathrm{Zn}$-face are not good Ohmic contacts even though their resistance is still low. Actually, the measured gold diodes can be viewed as two backto-back poor Schottky diodes. Thus, we see the increase in resistance with decreasing temperature. In addition, subsequent ROP treatment through the diodes changes only the $\mathrm{Au}$ diodes on the $\mathrm{Zn}$ face from Ohmic to rectifying, indicating different chemistry for oxygen plasma on the two polar surfaces.

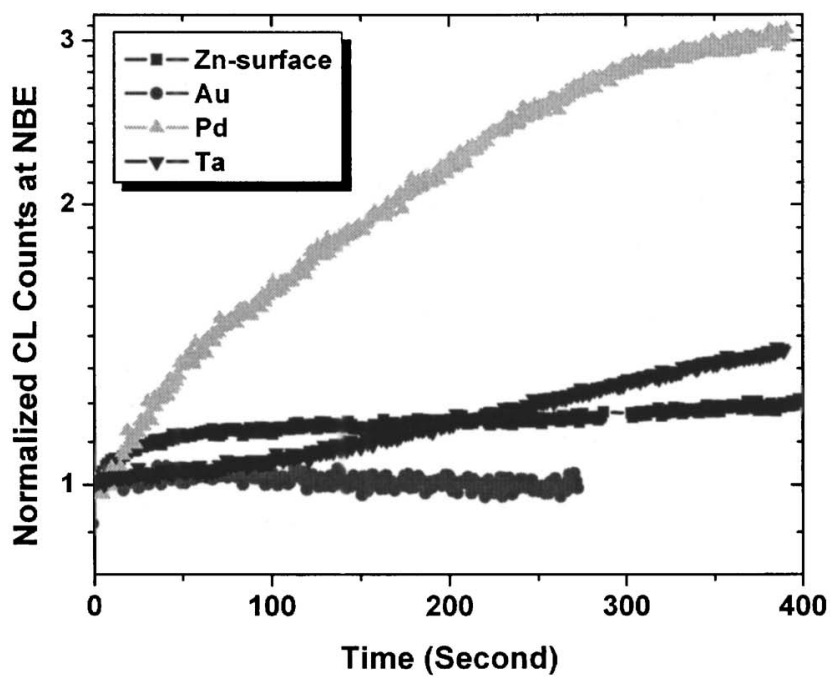

(a)

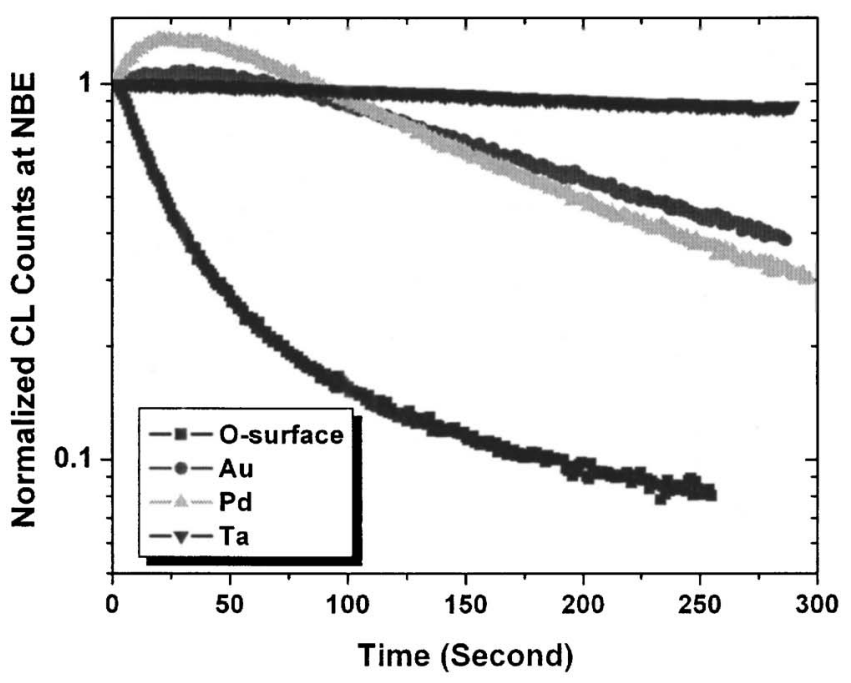

(b)

FIG. 3. CL time dependence of NBE emissions for Zn- and O-faces and their metal diodes.

For Au and Pd SBDs on ROP-treated surfaces, typical $I-V$ characteristics at $300 \mathrm{~K}$ in Fig. 5 show not only metal sensitivity but also a polarity dependence. In general, $\mathrm{Au} / \mathrm{Zn}$-face SBDs have ten times lower leakage current and higher rectification than Au/O-face SBDs. Pd SBDs always have larger currents than Au SBDs in the entire bias region, with $\mathrm{Pd}$ on the $\mathrm{Zn}$ face the highest. The $\mathrm{Pd} / \mathrm{ZnO}$ diode on the $\mathrm{Zn}$-face shows forward current bending at lower biases and seems to have a higher series resistance. Actually, this is due to higher leakage currents at both reverse and forward biases. The leakage currents might be related to field-enhanced localized current paths. ${ }^{12}$ Assuming that thermionic emission (TE) dominates forward current, then for $V>3 k T / q$, the current is $I=I_{S}\left\{\exp \left[q\left(V-I R_{S}\right) / \eta k T\right]-1\right\}$, with $I_{S}$ $=A A^{*} T^{2} \exp \left(-q \Phi_{\mathrm{SB}}^{I V} / k T\right)$ the saturation current, $R_{S}$ the series resistance, $\eta$ the ideality factor, $A$ the diode area $(1.25$ $\left.\times 10^{-3} \mathrm{~cm}^{2}\right), \quad A^{*}$ the effective Richardson constant 


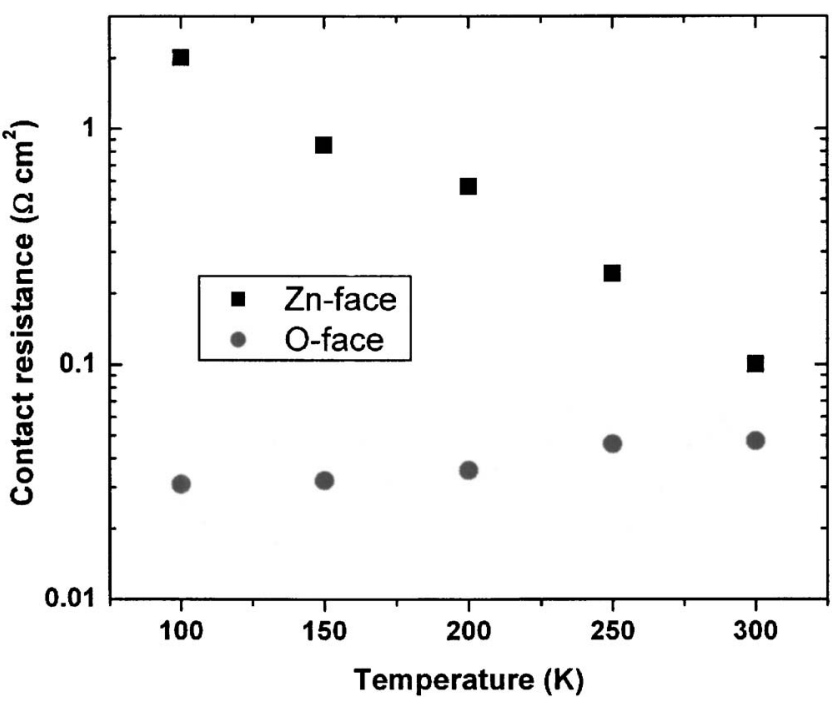

FIG. 4. Temperature-dependent contact resistances for two gold diodes on the $\mathrm{Zn}$-or O-faces.

$\left(32 \mathrm{~A} \mathrm{~cm}^{-2} \mathrm{~K}^{-2}\right)$, and $\Phi_{\mathrm{SB}}^{I V}$ the zero-biased SBH. Ideality factor $\eta$ and effective barrier heights from a TE model are summarized in Table I. Au SBDs have larger Schottky barrier height than Pd SBDs, notwithstanding the same work function values. ${ }^{24}$ Furthermore, the very different SBD behavior for the same metal, either $\mathrm{Au}$ or $\mathrm{Pd}$, on the $\mathrm{Zn}$ - or O-face indicates strong polarity effects. Note that the TE model alone cannot account for the large reverse currents, especially for Pd SBDs, where defect-assisted tunneling and/or hopping may play a role. Therefore, the barrier height evaluated from $I V$ for Pd SBDs may not be as accurate as that for $\mathrm{Au}$ SBDs. The nonideal characteristic of $\mathrm{Au}$ and Pd diodes may also be attributed to the inhomogeneous Schottky barriers. ${ }^{25,26}$ Temperature-dependent $I-V$ characteristics for $\mathrm{Au} / \mathrm{ZnO}$ and $\mathrm{Pd} / \mathrm{ZnO}$ SBDs will be reported elsewhere. ${ }^{30}$

We have carried out $C^{-2}-V$ measurements at $1 \mathrm{MHz}$, $100 \mathrm{kHz}$, and $10 \mathrm{kHz}$. Figure 6 shows the room temperature $C^{-2}-V$ characteristics at $1 \mathrm{MHz}$ for the same Au- and PdSBDs. The frequency dependence is negligible. Due to the small series resistance $\left(R_{S}, \sim 50 \Omega\right)$ for both $\mathrm{Au}$ and $\mathrm{Pd}$ SBDs, the criterion $R_{S} \ll(\omega C)^{-1}$ for the accurate determination of depletion capacitance can be satisfied at all frequencies. $\Phi_{\mathrm{SB}}^{C V}$ values were calculated from $\Phi_{\mathrm{SB}}^{C V}=V_{i}+V_{0}+k T / q$ with $V_{i}$ the intercept and $V_{0}=(k T / q) \ln \left(N_{C} / N_{D}\right) .{ }^{27}$ Note that $C^{-2}-V$ characteristics are linear only for O-face SBDs and they bend down for SBDs on the $\mathrm{Zn}$-face when approaching

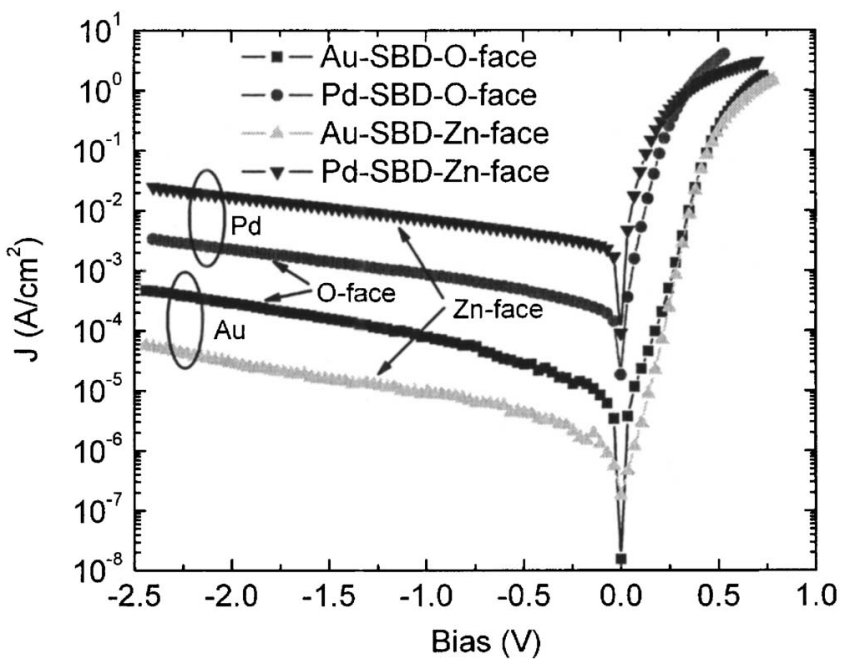

FIG. 5. Typical $I-V$ characteristics at $300 \mathrm{~K}$ for $\mathrm{Au}$ and Pd SBDs on ROP treated $\mathrm{Zn}$ - and $\mathrm{O}$-faces.

zero bias, which indicates the carrier inhomogeneity for $\mathrm{Zn}$ face with depth. Table I shows $\Phi_{\mathrm{SB}}^{C V}$ values for the SBDs extracted by linear fitting, which confirms the better rectifying behavior of Au than Pd SBDs. The evaluated $\Phi_{\mathrm{SB}}^{C V}$ values are larger than $\Phi_{\mathrm{SB}}^{I V}$, especially for Au diodes, indicating the lateral inhomogeneity. The associated carrier density profiles as shown in Fig. 7 are strongly polarity- and metal dependent. There are two important features: (i) net carrier concentrations $\left(N_{d}-N_{a}=N_{\text {eff }}\right)$ are constant for both the Au and Pd SBDs on the O-face in the near surface region (90-170 nm), whereas they gradually decrease by about $30 \%$ in the same region for $\mathrm{Au}$ and $\mathrm{Pd}$ on the Zn-polar surface; and (ii) $N_{d}$ increases sharply for the Pd SBDs on both polar surfaces at the shallowest depths profiled by $C-V$. Similar decrease in surface carrier concentration was also found for Pt diodes on sulfide treated $\mathrm{ZnO} O$ faces $^{28}$ and for Pd on hydrogen peroxide treated $\mathrm{ZnO} O$ faces. ${ }^{6}$ But this is the first report of the polarity dependence for ROP cleaned surfaces. Note that due to higher currents at zero bias on $\mathrm{Pd} / \mathrm{ZnO}$ diodes, as compared to $\mathrm{Au} / \mathrm{ZnO}$ diodes, larger conductance is involved in the capacitance measurement, which may contribute to the sharp increase in carrier concentration at near surface region. Nevertheless, large conductance and sharp increase in $N_{d}$ indicate a surface conductive layer at $\mathrm{Pd} / \mathrm{ZnO}$ interfaces.

The observed decrease in carrier concentration at the near surface region of $\mathrm{Zn}$-face is closely related to oxygen plasma treatment, which further decreases toward the surface with

TABLE I. SBD characteristics at $300 \mathrm{~K}$ for Pd and $\mathrm{Au}$ on $\mathrm{Zn}$ - and O-polar surfaces.

\begin{tabular}{lccccc}
\hline \hline Surface & $\begin{array}{c}\text { Schottky } \\
\text { metal }\end{array}$ & $\begin{array}{c}\text { Ideality } \\
\eta\end{array}$ & $\begin{array}{c}\Phi_{\mathrm{SB}}^{I V} \\
(\mathrm{eV})\end{array}$ & $\begin{array}{c}\Phi_{\mathrm{SB}}^{C V} \\
(\mathrm{eV})\end{array}$ & $\begin{array}{c}\mathrm{Nd}-\mathrm{Na} \\
\left(\times 10^{17} \mathrm{~cm}^{-3}\right)\end{array}$ \\
\hline$(0001) \mathrm{Zn}$ & $\mathrm{Au}$ & 1.2 & 0.81 & 1.20 & $0.7-1.0$ \\
$(0001) \mathrm{Zn}$ & $\mathrm{Pd}$ & 1.3 & 0.53 & 0.73 & $0.8-1.0$ \\
$(000 \overline{1}) \mathrm{O}$ & $\mathrm{Au}$ & 1.3 & 0.77 & 1.07 & 1.1 \\
$(000 \overline{1}) \mathrm{O}$ & $\mathrm{Pd}$ & 1.2 & 0.61 & 0.68 & 1.1 \\
\hline
\end{tabular}




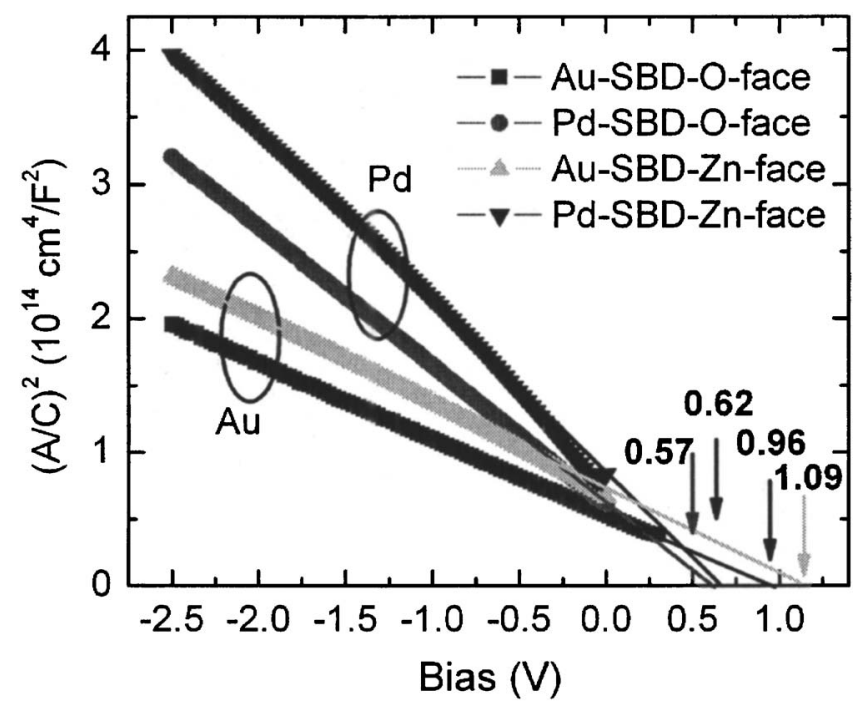

Fig. 6. Typical $1 / C^{2}-V$ curves at $300 \mathrm{~K}$ for Au- and Pd-SBDs on ROP treated $\mathrm{Zn}$ - and $\mathrm{O}$-faces.

increasing ROP time, while that at the O-face is independent of ROP time. The oxygen plasma is much more likely to react with the $\mathrm{Zn}$-face than with the $\mathrm{O}$-face. Because there is no obvious new defect CL emission other than the $2.5 \mathrm{eV}$ emission (due to oxygen vacancy) after up to $2 \mathrm{~h}$ ROP, the possibility of $\mathrm{Zn}$ vacancy formation (as deep acceptor) can be excluded, since $\mathrm{Zn}$ vacancy-related defects should have an emission peak around $2.1 \mathrm{eV}$ if present. ${ }^{9}$ Hydrogen removal from surface regions can also decrease the carrier profile by decreasing donor density or activating acceptor impurities. Conversely, a previous study found that remote hydrogen plasma treatment increased surface electron concentration in single crystal $\mathrm{ZnO} .{ }^{29}$ Consistent with hydrogen removal, recent $4.2 \mathrm{~K}$ PL shows that ROP reduces the $I_{4}$ line at $3.368 \mathrm{eV}$ assigned to hydrogen donor bound exciton on the $\mathrm{Zn}$-face but much less on the O-face for the same samples. ${ }^{30}$ First principles calculations provide further evidence that it is much easier for hydrogen to diffuse out of the $\mathrm{Zn}$ face ${ }^{31}$ However, there is no asymmetry for oxygen diffusion within $\mathrm{ZnO}^{32}$ Therefore, we propose several points about the polarity-related ROP effects: (i) ROP cleans both surfaces by removing surface adsorbates; (ii) ROP effectively removes hydrogen from the $\mathrm{Zn}$ face and dissociates $V_{\mathrm{O}}-\mathrm{H}$ complexes within the near surface region; (iii) ROP decreases $V_{\mathrm{O}}$ density on the $\mathrm{O}$ face, which was shown by the decrease in CL defect emission, but have no effect on the carrier profile as $V_{\mathrm{O}}$ is a deep level; and (iv) ROP can also decrease $V_{O}$ density on the $\mathrm{Zn}$ face, although the decrease in free carrier density is dominated by the dissociation of $V_{\mathrm{O}}-\mathrm{H}$ complexes. Thus, while ROP removes $\mathrm{O}$ vacancies and $\mathrm{H}$ from both surfaces, the higher $\mathrm{O}$ vacancy concentration and lower $\mathrm{H}$ removal rate at the $\mathrm{O}$ surface result in higher near surface carrier concentrations at the $\mathrm{O}$ face.

$\mathrm{ZnO}$ has strong spontaneous polarization along the $\langle 0001\rangle$ direction, which can induce electron accumulation/depletion on the ideal $\mathrm{O} / \mathrm{Zn}$ faces and make $n$-type SBDs easier to form on the $\mathrm{Zn}$ face. ${ }^{17,33}$ However, metal diodes on as-

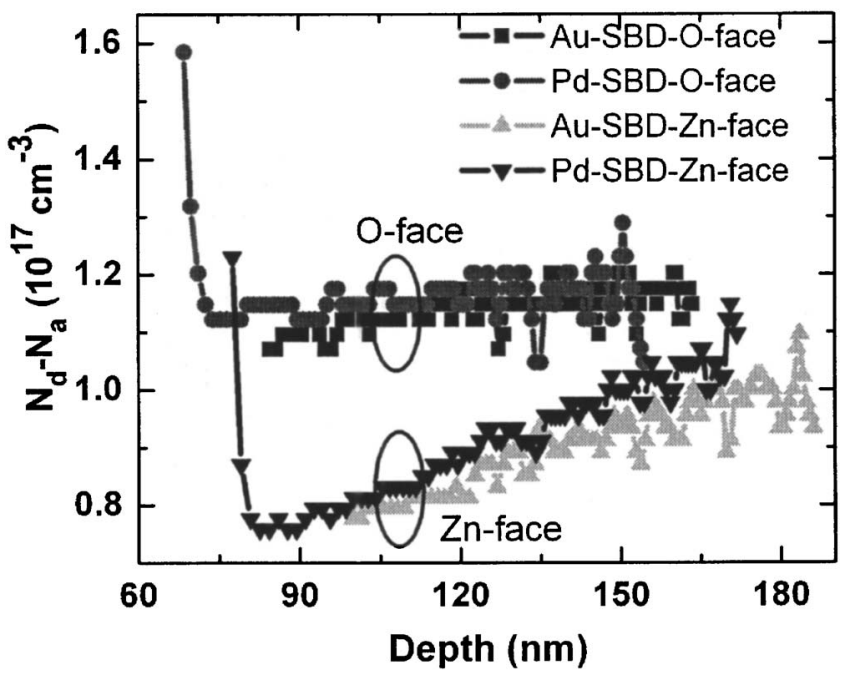

FIG. 7. Near surface carrier-concentration profiles for Au- and Pd-SBDs on ROP treated $\mathrm{Zn}$ - and O-faces.

received $\mathrm{Zn}$ and $\mathrm{O}$ faces are Ohmic which indicates electron accumulation on both surfaces due to surface adsorbates. ROP can effectively remove surface adsorbates. But it is difficult to stabilize the ideal $\mathrm{Zn}$ face in an O-rich atmosphere. ${ }^{16}$ Therefore, we argue that spontaneous polarization is not the dominant role that decides the polarity effects found here.

With increasing ROP time from 1 to $2 \mathrm{~h}$, the SBDs' rectification increases, regardless of the surface polarity. But the polarity dependence and metal sensitivity are still significant. Our DLTS reveals the evolution of defect traps with ROP time. E3 is the dominant trap for all SBDs. It is closely related to ROP, increasing with ROP exposure time on both surfaces but only shifting in energy on the $\mathrm{Zn}$ face. One surface trap Es was only found for Pd SBD on $1 \mathrm{~h}$ ROP cleaned Zn-face, consistent with DRCL results. ${ }^{12}$ The detailed DLTS results will be reported elsewhere. ${ }^{30}$

The surface conductive layer at $\mathrm{Pd} / \mathrm{ZnO}$ interfaces is due to hydrogen diffusion. It is easy for hydrogen to penetrate the thin Pd film and accumulate at interfaces. Our PL data indicate that this accumulation is larger for the $\mathrm{Zn}$-face. Figure 8 shows low temperature $(80 \mathrm{~K}) \mathrm{PL}$ spectra for ROP treated bare Zn-face, Pd, and Au SBDs. Pd SBDs exhibit a much larger $I_{4}$ peak increase, compared with Au SBDs. Pd SBDs exhibit a similar enhancement on the O-face but in smaller magnitude. Interface $\mathrm{H}^{+}$acts as donors, forms negative interface dipole with its image charge on the metal side, and decreases Schottky barriers at $\mathrm{Pd} / \mathrm{ZnO}$ interfaces. We calculated the interface Fermi level position as a function of H-related surface donor density, as shown in Fig. 9. In Schottky limit, barrier height is given by the energy difference of metal work function $\left(\Phi_{M}\right)$ and semiconductor electron affinity (EA), while in Bardeen limit the interface Fermi level is pinned close to the defect level. $\mathrm{ZnO}$ has an EA around $4.0-4.4 \mathrm{eV}$, depending on surface properties. With a negative interface dipole $\Delta V$, the Schottky barrier height $\Phi_{B}$ 


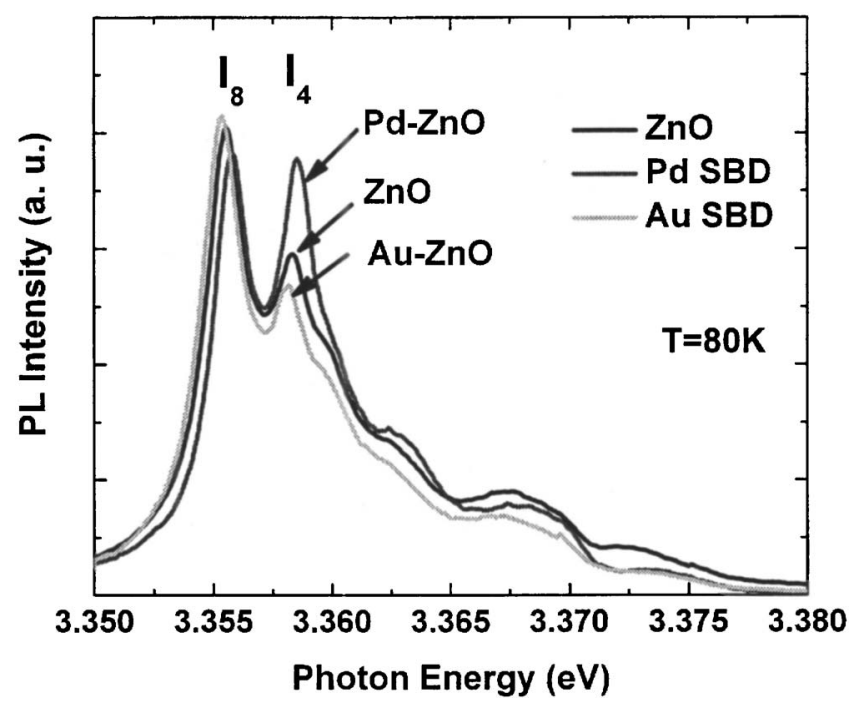

FIG. 8. $80 \mathrm{~K}$ PL for $\mathrm{ZnO}$ surfaces and Pd/Au SBDs.

is given by $\Phi_{B}=\Phi_{M}-\mathrm{EA}-|\Delta V|$. As shown by Fig. 9, Schottky barrier is reduced by $\sim 0.4 \mathrm{eV}$ with $10^{13} / \mathrm{cm}^{2}$ surface donor density.

To account for these metal- and polarity-dependent carrier concentration profiles, we propose a comprehensive model and describe the effective donor concentration $N_{d}^{\text {eff }}$ as

$$
N_{d}^{\text {eff }}=N_{d}^{\text {bulk }}+N_{d}^{\text {surf }} \exp \left(-z / d_{1}\right)-N_{a}^{\text {surf }} \exp \left(-z / d_{2}\right),
$$

where $N_{d}^{\text {bulk }}$ is the bulk donor concentration and $N_{d}^{\text {surf }}$ and $N_{a}^{\text {surf }}$ are surface donor and acceptor densities decaying away from the surface with decay lengths $d_{1}$ and $d_{2}$, respectively. The sharp $N_{d}$ increase for Pd SBDs near the surface is due to hydrogen incorporation at the interface and it is consistent with the most leaky $I-V$ characteristic for Pd SBDs on the $\mathrm{Zn}$-face. The $N_{d}^{\text {surf }}$ term describes the sharp $N_{d}^{\text {eff }}$ increase within the outer few nanometers due to $\mathrm{H}$ and perhaps to impurity segregation from the bulk. ${ }^{34} \mathrm{~A} N_{a}^{\text {surf }}$ surface acceptor term with $d_{2} \sim 100 \mathrm{~nm}$ accounts for the $\mathrm{Zn}$-face $N_{d}^{\text {eff }}$ subsurface decrease, possibly due to the polarity-dependent

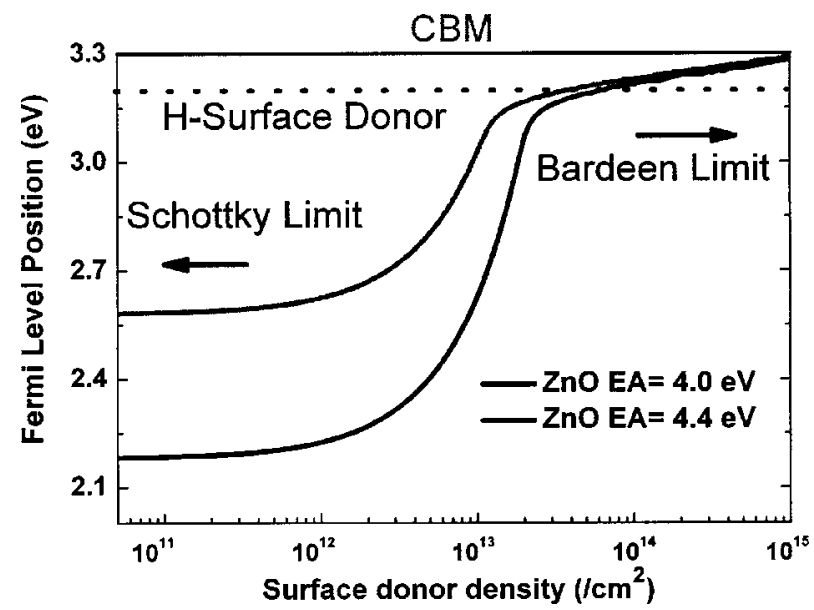

FIG. 9. Calculated interface Fermi level as a function of surface $\mathrm{H}^{+}$donor density.

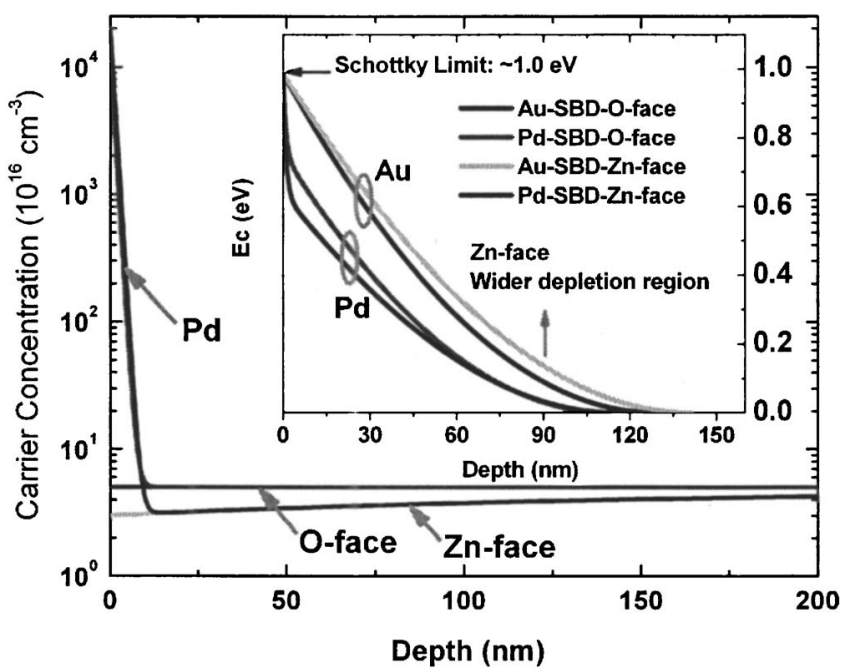

FIG. 10. Carrier concentration profiles and calculated conduction band diagrams for $\mathrm{Au}$ and $\mathrm{Pd}$ SBDs on the $\mathrm{Zn}$ - and O-faces.

H-removal. With reasonable values assigned to the terms in Eq. (1) and by solving Poisson's equations, the carrier profile and associated conduction band diagram are shown in Fig. 10. The rapidly increasing $N_{d}^{\text {eff }}$ near the $\mathrm{Pd} / \mathrm{ZnO}(0001)$ and $(000 \overline{1})$ interfaces narrows the surface space charge region and forms an ultrathin surface barrier, which also represents the negative interface dipole $\Delta V$. Thus tunneling through a hydrogen-induced interface dipole decreases the effective Schottky barrier. In addition, introduction of $N_{d}^{\text {surf }}$ widens the SBDs' depletion region on the Zn versus O-face. The revised band bending is consistent with the Table I values of $\Phi_{\mathrm{SB}}^{C V}$ and $\Phi_{\mathrm{SB}}^{I V}$ and accounts for the metal and polarity dependences.

\section{CONCLUSION}

The polarity-related asymmetry in $\mathrm{ZnO} c$-plane polar surfaces and metal diodes has been studied by DRCLS and electrical measurements. Significant optical polarity signatures have been found for the $\mathrm{Zn}$ - and O-faces in CL, including higher oxygen vacancy density and faster evolution with exposure time on the $\mathrm{O}$ face. $\mathrm{Au}$ and $\mathrm{Pd}$ diodes on asreceived and $\mathrm{O}_{2} / \mathrm{He}$ plasma-cleaned surfaces display not only a significant metal sensitivity but also a strong polarity dependence that correlates with defect emissions, traps, and interface chemistry.

\section{ACKNOWLEDGMENT}

The authors gratefully acknowledge support from the National Science Foundation Grant No. DMR-0513968 (Verne Hess).

${ }^{1}$ S. J. Pearton, D. P. Norton, K. Ip, Y. W. Heo, and T. Steiner, Prog. Mater. Sci. 50, 312 (2005).

${ }^{2}$ B. J. Coppa, R. F. Davis, and R. J. Nemanich, Appl. Phys. Lett. 82, 400 (2003).

${ }^{3}$ H. L. Mosbacker, Y. M. Strzhemechny, B. D. White, P. E. Smith, D. C. Look, D. C. Reynolds, C. W. Litton, and L. J. Brillson, Appl. Phys. Lett. 87, 012102 (2005). 
${ }^{4}$ M. W. Allen, M. M. Alkaisi, and S. M. Durbin, Appl. Phys. Lett. 89, 103520 (2006).

${ }^{5}$ M. W. Allen and S. M. Durbin, Appl. Phys. Lett. 92, 122110 (2008).

${ }^{6}$ R. Schifano, E. V. Monakhov, U. Grossner, and B. G. Svensson, Appl. Phys. Lett. 91, 193507 (2007).

${ }^{7}$ Q. L. Gu et al., J. Appl. Phys. 103, 093706 (2008).

${ }^{8}$ K. Ip, G. T. Thaler, H. Yang, S. Y. Han, Y. Li, D. P. Norton, S. J. Pearton,

S. Jang, and F. Ren, J. Cryst. Growth 287, 149 (2006).

${ }^{9}$ L. J. Brillson et al., Appl. Phys. Lett. 90, 102116 (2007).

${ }^{10}$ H. L. Mosbacker et al., Appl. Phys. Lett. 91, 072102 (2007).

${ }^{11}$ Y. Dong and L. J. Brillson, J. Electron. Mater. 37, 743 (2008).

${ }^{12}$ Z.-Q. Fang, B. Claflin, D. C. Look, Y. F. Dong, H. L. Mosbacker, and L. J. Brillson, J. Appl. Phys. 104, 063707 (2008).

${ }^{13}$ Y. Dong, Z.-Q. Fang, D. C. Look, G. Cantwell, J. Zhang, J. J. Song, and L. J. Brillson, Appl. Phys. Lett. 93, 072111 (2008).

${ }^{14}$ L. K. Li, M. J. Jurkovic, W. I. Wang, J. M. Van Hove, and P. P. Chow, Appl. Phys. Lett. 76, 1740 (2000).

${ }^{15}$ S. Lautenschlaeger, J. Scann, N. Volbers, B. K. Meyer, A. Hoffmann, U. Haboeck, and M. R. Wagner, Phys. Rev. B 77, 144108 (2008).

${ }^{16}$ C. Woll, Prog. Surf. Sci. 82, 55 (2007).

${ }^{17}$ M. W. Allen, P. Miller, R. J. Reeves, and S. M. Durbin, Appl. Phys. Lett. 90, 062104 (2007).

${ }^{18}$ S. A. Chevtchenko, J. C. Moore, Ü. Özgür, X. Gu, A. A. Baski, H. Morkoç, B. Nemeth, and J. E. Nause, Appl. Phys. Lett. 89, 182111 (2006).

${ }^{19}$ D. C. Look, Mater. Res. Soc. Symp. Proc. 957, 127 (2007).
${ }^{20}$ D. C. Look and Z.-Q. Fang, Appl. Phys. Lett. 79, 84 (2001).

${ }^{21}$ B. Dierre, X. L. Yuan, and T. Sekiguchi, J. Appl. Phys. 104, 043528 (2008).

${ }^{22}$ M. Allen et al., Mater. Res. Soc. Symp. Proc. 1035, L10-06 (2008).

${ }^{23}$ O. Schmidt, A. Geis, P. Kiesel, C. G. V. de Walle, N. M. Johnson, A. Bakin, A. Waag, and G. H. Dohler, Superlattices Microstruct. 39, 8 (2006).

${ }^{24}$ H. B. Michaelson, J. Appl. Phys. 48, 4729 (1977).

${ }^{25}$ H. Sheng, S. Muthukumar, N. W. Emanetoglu, and Y. Lu, Appl. Phys. Lett. 80, 2132 (2002).

${ }^{26}$ H. von Wenckstern, G. Biehne, R. A. Rahman, H. Hochmuth, M. Lorenz, and M. Grundmann, Appl. Phys. Lett. 88, 092102 (2006).

${ }^{27}$ D. K. Schroder, Semiconductor Material and Device Characterization (Wiley, New York, 1998).

${ }^{28}$ S.-H. Kim, H.-K. Kim, and T.-Y. Seong, Appl. Phys. Lett. 86, 022101 (2005).

${ }^{29}$ Y. M. Strzhemechny et al., Appl. Phys. Lett. 84, 2545 (2004).

${ }^{30}$ Z.-Q. Fang, B. Claflin, D. C. Look, Y. Dong, and L. J. Brillson, J. Vac. Sci. Technol. B (in press).

${ }^{31}$ M. G. Wardle, J. P. Goss, and P. R. Briddon, Phys. Rev. Lett. 96, 205504 (2006).

${ }^{32}$ A. Janotti and C. G. Van de Walle, Phys. Rev. B 76, 165202 (2007).

${ }^{33}$ D. C. Oh, T. Kato, H. Goto, S. H. Park, T. Hanada, T. Yao, and J. J. Kim, Appl. Phys. Lett. 93, 241907 (2008).

${ }^{34}$ D. C. Look, B. Claflin, and H. E. Smith, Appl. Phys. Lett. 92, 122108 (2008). 